\title{
FILOSOFÍA PARA DAMAS HOY: EL MUNDO DE SOFÍA
}

\author{
Carmen Mataix Loma \\ Universidad Complutense de Madrid
}

ABSTRACT The author compares one of the philosophical best sellers, Sophia's World, with traditional "literature for Ladies", a very famous genre in the Enlightenment. The book supports masculine-feminine duality as well as adult-child and reality-appearance dualities.

KEY WORDS Literature for Ladies. Masculine-femenine. Reality vs. appearance.
RESUMEN La autora compara uno de los libros de divulgación fiosófica de más éxito, El mundo de Sofía, con la tradicional «literatura para damas" desarrollada como género en la llustración. El libro mantiene la dualidad masculino-femenino, a la vez que la de adulto-niño y la tradicional filosófica, apariencia-realidad.

PALABRAS CLAVE Literatura para damas. Masculino-femenino. Realidad vs. apariencia.
La primera sorpresa que obtuve cuando lei El mundo de Sofia ${ }^{1}$ fue la de constatar que aún hoy se sigue escribiendo lo que se ha dado en Ilamar filosofía para damas. El presente trabajo pretende ser un análisis del mencionado libro, -que ha sido un best seller en los últimos años-, sobre esa base, ya que, en sus rasgos generales cumple una serie de caracteristicas, la primera de las cuales es genérica, en todas las acepciones del término:

En primer lugar, la estructura del libro mantiene una primera dualidad masculino-femenino, que además comporta otras dos: la dualidad filosófica tradicional, apariencia-realidad y la dualidad adulto-niño.

Antes de hablar de las dos últimas, conviene analizar la primera porque pone de relieve lo que el libro pretende ser: una suerte de diálogo entre dos personas de distinto género. Sin embargo, las especiales caracteríticas del mismo, y de sus protagonistas, ponen en juego las otras dos dualidades y estructran el libro como uno más de lo que en el siglo XVIII se llamó filosofía para damas. La asiduidad con la que científicos e intelectuales de la época frecuentaban los salones de algunas damas francesas de la aristocracia o la burguesía llevó a aquellos a escribir un cierto género de literatura científica encaminado fundamentalmente a instruir a sus anfitrionas o sus acompañantes. Así se escribió un famoso libro de Algarotti, Newtonianismo para damas cuyo título no dejaba lugar a dudas acerca de lo que pretendia ser: una explicación más o menos profunda del newtonianismo (en este caso se trata más de la Optica que de la Mecánica de Newton), al alcance de la limitada capacidad e información de las féminas.

Pero el fenómeno se puso de moda, y desde el siglo XVIII se produce una cierta competencia entre los filósofos y los científicos en intentar hacer llegar a las damas una cierta información y formación sobre la filosofia y la ciencia del momento, disputándose estos mismos científicos la concurrencia a los famosos salones parisinos mantenidos por algunas de las damas destinatarias de tales libros.

Entre la literatura de este tipo, encontramos dos variantes. La primera va dirigida a mujeres aristócratas que mantienen una correspondencia con filósofos, como es el caso de la reina Cristina de Suecia con Descartes, las cartas de Euler a la sobrina del rey de Prusia, o las varias princesas a las que se ha dirigido Leibniz. En este caso, estas damas constituyen interlocutores reales, si bien con mucha menos información que el varón cuya misión es precisamente instruirlas. Como comenta A. Rioja en su Introducción a las Reflexiones sobre el espacio, la fuerza y la materia, recogiendo textos de las Cartas a una princesa alemana, éstas suponen "un conjunto de cartas (exactamente 234) escritas en Berlin entre abril de 1760 y mayo de 1762 dirigidas a la sobrina del rey de Prusia, Friederike Charlotte Ludovica Luise, futura princesa 
de Anhalt-Dessau de,15-17 años de edad, a petición de su padre, Friedrich Heinrich von Brandenburg-Schwelt. Éste, en efecto, había solicitado a Euler que se encargara de la instrucción de su hija. El hecho de que se dirigía a una persona de pocos conocimientos, justifica la extraordinaria sencillez y simplicidad con que están escritas. No le extrañe, pues al lector, -comenta Rioja- ver a un autor de la talla de Euler explicar pacientemente cómo se halla el cuadrado de un número o en qué se diferencia una relación directamente proporcional de una relación inversalmente proporcionalı².

Por su parte, Leibniz, como ya he mencionado antes, es uno de los más prolíficos autores dirigido hacia las damas. El sugerente y precioso título del libro de Javier Echeverría Filosofia para Princesas recoge precisamente algunas de estas cartas, y como muy bien explica Echeverría en la Introducción, el titulo abarca no sólo a las princesas reales con las que Leibniz mantuvo correspondencia, sino también a todas nosotras, hipotéticas princesas en "edad de merecer", es decir, de aprender. "Tal es el sentido último de la obra que tienes a la vista, -escribe Echeverria en su Introducción. Por mucha que sea la distancia temporal, espacial o cultural, estas cartas de Leibniz también están dirigidas a tí. Te permitirán conocer algo mejor la condición de princesa y filósofa. Al cabo, igual te toca gobernar, ser reina. En un ámbito 0 en otron ${ }^{3}$.

Pues, en efecto, como explica A. Rioja en el libro citado se puso de moda en el XVIII abrir los salones y que las mujeres participaran plenamente en ellos, "convirtiéndose en lugares de extraordinaria influencia. Recordemos a una Mme. de Châtelet, amante de Voltaire y traductora al francés de los Principia Mathematica de Newton, a una Mme. de Geoffrin, en cuyas reuniones y tertulias no era dificil encontrar a Rousseau, D'Alambert o Diderot, a una Mlle. de Coigny o a una Mme. de Pompadour, y a otras tantas" ${ }^{4}$.

Un segundo caso lo conforman los escritos dirigidos a una mujer hipotética, ideal. No es tanto la interlocutora válida con la que se mantiene un diálogo, sino más bien un personaje ficticio que sirve de pretexto para que el autor vaya desvelando la información y vaya así sacando de la ignorancia a su evanescente discipula. Dentro de este segundo tipo se situaría la obra de Fontenelle Conversaciones sobre la pluralidad de los mundos.
La dama a la que presuntamente va dirigido el escrito y que hace de interlocutora, no es, en ningún modo un personaje informado, sino bien al contrario manifiesta en todo momento su sorpresa por los temas que va descubriendo. Juega más el papel del personaje socrático al que se le va haciendo reflexionar para encaminarle al descubrimiento de la verdad, en la hipótesis de que él mismo va a hacer explicito lo que ya conocia sin saberlo, lo supone implicitamente una determinada teoria sobre el conocimiento; en cierta medida es más similar al Simplicio galileano, pero sin las connotaciones aristotélicas del mismo. Por otra parte, el personaje galileano no es un ser que ignore todo, como en el supuesto de Fontenelle, sino un aristotélico convencido dispuesto a mantener unas ideas en medio de un contexto adverso; el resultado es que, frente a Salviati, defensor de las tesis galileanas, Simplicio no es ni neutral, ni ignorante, sino en todo caso un interlocutor situado en una plataforma cultural supuestamente caduca. Por eso el ingenio de Galileo en sus diálogos queda repartido entre sus agudas argumentaciones a favor del heliocentrismo y un cierto tono irónico para desprestigiar a tan incómodo contrincante, naturalmente varón.

No es este, en absoluto, el caso de Fontenelle como hace saber él mismo: "He puesto en esas Conversaciones a una mujer a la que se instruye y que no ha oído hablar jamás de estos asuntos. He creído que esta ficción me servia no tanto para hacer la obra más susceptible de resultar amena, como para animar a las damas con el ejemplo de una mujer que, sin sobrepasar los límites de quien no tiene ningún barniz de ciencia no deja de entender lo que se dice y de ordenar en su mente sin confusión, los torbellinos y los mundos. ¿Por qué habrian de ceder las mujeres a esta marquesa imaginaria que no concibe más que lo que no puede dejar de concebir?» 5 .

Pasando ahora a analizar el libro de Gaarder cuya publicación es del año 1991 las semejanzas con la obra de Fontenelle resultan curiosas y merecen algún comentario.

En primer lugar, la protagonista de éste último es un personaje de ficción: Sofía, que se situa como interlocutora dispuesta a recibir las enseñanzas del maestro, pero sin ideas preconcebidas, sino como la protagonista de Fontenelle, un ser que no ha oido hablar jamás de estos asuntos. Ignoro si Sofia,la destinataria del libro que lleva su nombre existe, aunque me atrevo a suponer que sí, como también lo pienso de la supuesta Marquesa del de Fontenelle, y como exis- 
tió la famosa Alicia de Lewis Carroll a la que éste inmortalizó en Alicia en el Pais de las maravillas y de la que tal vez merezca la pena un comentario en otro momento. En cualquier caso los dos comienzan con una descripción del paisaje que permita al lector introducirle en el contexto: "Una noche, después de cenar, fuimos a pasear por el parque. Hacía un fresco delicioso que nos recompensaba por un dia de mucho calor que habiamos padecido. Hacia como una hora que la Luna había salido y sus rayos, que no llegan a nosotros más que a través de las ramas de los árboles, producian una agradable combinación de un blanco muy vivo, con todo el verde que parecía negro. No había una sola nube que ocultara u oscureciera la estrella más pequeña. Todas ellas eran de un oro puro y resplandeciente que se intensificaba más aún por el fondo azul en el que están fijas. Este espectáculo me hizo soñar y quizá, a no ser por la marquesa, me hubiera ensimismado durante bastante más tiempon 6 .

"Sofia Amundsen -escribe Gaarder- volvía a casa después del Instituto. La primera parte del camino la habia hecho en compañia de Jorunn.... Se habian despedido junto al hipermercado. Sofia vivia al final de una gran urbanización de chalets, y su camino al instituto era casi el doble que el de Jorunn. Era como si su casa se encontrara en el fin del mundo,pues más allá de su jardin no había ninguna casa más. Alli comenzaba el espeso bosque»?.

Es obvio que esta situación descriptiva del contexto es necesaria por el hecho de que no son personajes reales y por lo tanto el lector no conoce previamente nada de ellos; esto marca una gran distancia con el otro tipo de libros ya que en ellos conocemos perfectamente el personaje al cual van dirigidos: para ninguna de las "princesas" de Leibniz -las sofias leibnizianas, Sofía, princesa de Hannover y Sofia Carlota reina de Prusia- se hacía necesario situarlas en un contexto que permita definir la edad (el instituto, en la Sofía de Gaarder), ni el entorno palaciego de la marquesa de Fontenelle.

Este segundo tipo de libros al que me estoy refiriendo marca un estilo distinto ya que como base supone una clara desigualdad entre los dos interlocutores: uno de ellos, el maestro, varón, frente al otro, ignorante y naturalmente, mujer. El destinatario adquiere hacia su "maestro" una actitud entre la admiración y el agradecimiento que inevitablemente tiene que traducirse en un cierto paternalismo carcterístico de esta clase de obras, sean de la época que sean.
En el caso de El mundo de Sofía el paternalismo viene doblemente acentuado porque, al tratarse de una adolescente, el personaje masculino se entrecruza en un ambiguo juego, con la figura del padre de Sofía, o al menos del de una protagonista paralela en esa dualidad imagen/realidad, a la que aludi al comienzo.

Ya en sus primeras páginas se plantea una pregunta crucial, ante las muchas preguntas "cruciales" que un, por ahora desconocido, le ha planteado a la protagonista: "¿Quién había arrancado a Sofía de lo cotidiano para de repente ponerla ante los grandes enigmas del universo?» ${ }^{8}$. En la respuesta, el lector está ya suponiendo que el responsable de semejante tarea es, desde luego, un varón.

En el caso de Fontenelle el estilo paternalista con el que él se dirije a la Marquesa, se manifiesta en la demostración de una cierta admiración fingida por su capacidad de comprensión que contrasta, por otra parte, con la descripción que de ella ha hecho al comienzo del libro, como alguien sin ningún tipo de conocimientos previos, ni de ideas preconcebidas: "No sé -le respondí- quién os ha dado ideas tan sanas, pero ciertamente no es demasiado frecuente tenerlas. La mayoria de las personas tienen siempre en la cabeza un algo falsamente maravilloso envuelto por una oscuridad que respetan. No admiran la naturaleza, sino porque la creen una especie de magia en la que no se entiende nada. $Y$ es seguro que queda desprestigiada a sus ojos cuando puede ser comprendida. Pero vos señora -continué- estais tan bien preparada para acceder a todo lo que voy a a deciros, que creo que no tengo más que correr el telón y mostraros el mundon".

En el libro de Gaarder también aparece con frecuencia el tono paternalista, acentuado, como dije, por el papel que representa en este caso la figura del padre.

"Un filósofo jamás ha sabido habituarse del todo al mundo. Para él o ella, el mundo sigue siendo algo desmesurado, incluso algo enigmático y misterioso. Por lo tanto los filósofos y los niños pequeños tienen en común esa importante capacidad. Se podria decir que un filósofo sigue siendo tan susceptible como un niño pequeño durante toda la vida. De modo que puedes elegir, Sofía, ¿eres una niña pequeña que aún no ha llegado a ser la perfecta conocedora del mundo? ¿o eres una filósofa que puede jurar que jamás lo llegará a conocer? Si simplemente niegas con la cabeza y no te reconoces ni en el niño ni en el filósofo, es porque tú 
también te has habituado tanto al mundo que te ha dejado de asombrar. En ese caso corres peligro. Por esa razón recibes este curso de filosofía, es decir, para asegurarnos. No quiero que tú justamente estés entre los indolentes e indiferentes. Quiero que vivas una vida despierta» ${ }^{10}$.

El texto señalado en negrita va más allá y muestra un estilo con toques incluso moralizantes: Sofía corre peligro, y la instrucción que se le está aportando tiene una finalidad: se trata de asegurarnos. Pero, ¿quién tiene que tener esa garantía de seguridad?. Obviamente no es la destinataria, sino el instructor, varón adulto, que, al parecer, está ya fuera de peligro. Y el autor continua explicando la actitud de "santa ignorancia" (que no de docta, como en Cusa) en la que está Sofía hasta el momento del encuentro con su mentor. "iHabia tantas cosas en las que nunca había pensado antes! Ya no era una niña, pero tampoco era del todo adulta" ${ }^{11}$.De haberlo sido, cuesta trabajo creer que a finales del siglo XX se pueda atrever un autor a dirigirse a una mujer en ese tono.

Otro elemento destacable en este tipo de literatura es que el discurso está siempre envuelto en una cierta trama de intriga. Esto tampoco sucede cuando el interlocutor es varón, por muy ignorante que pudiera ser. Volviendo al ejemplo de los Diálogos galileanos, que puse al principio, por mucha ironía latente o explicita que pueda haber respecto del personaje aristotélico, o por muy ignorante que pudiera ser el moderador, Sagredo, no aparece esta idea de misterio que envuelve a este tipo de diálogos, cuando el receptor es un personaje femenino. Asi, en el caso de Fontenelle, el tema mismo manifiesta un carácter criptico, la mera existencia de la pluralidad de mundos y, consiguientemente, la posibilidad de que estén habitados. Esto deja al lector sumido en la expectativa de la solución ya que, sea esta positiva o negativa, las dos son inquietantes. ¿Estamos solos ante una pluralidad de mundos vacíos, o estamos, por el contrario, rodeados de otros seres de los que ignoramos todo? Aún hoy esto causa expectación y recelo. Pues bien, si el objeto de diálogo resulta misterioso, la actitud jerárquica del interlocutor masculino frente al femenino ante el problema en cuestión dota a la obra de un aspecto de intriga que la sitúa entre la complicidad y el secreto; es como si se estableciera una cierta complicidad con el lector, conocedor de las verdades que se van a revelar a la discipula en cuestión. Un tema como el tratado por Fontenelle resulta indudablemente mucho más espectacular si frente a él tiene a una persona que nunca ha oido hablar de nada parecido; con

ARBOR CLXXXI 716 NOVIEMBRE-DICIEMBRE (2005) 493-499 ISSN: 0210-1963 este recurso el carácter de misterio se acentua todavía más. El mismo autor, en el tono paternalista ya aludido, reconoce tener que suavizar un poco el asunto:

"Puedo jactarme -repliqué- de haberos edulcorado todo el sistema. Si os lo diese tal como fue concebido por Ptolomeo, su autor, o por los que lo han trabajado después de él, os llenaría de un horrible espanto» 12 .

Y más adelante, después de aclarar en qué sentido se puede producir tal espanto, pero sin precisar demasiado, dada la ignorancia de la marquesa y lo complicado del tema, Fontenelle aclara esta complicación diciendo: «El embrollo de todos los circulos era tan grande que, en una época en que no se conocia aún nada mejor, un rey de Castilla, gran matemático, pero al parecer poco devoto, dijo que si Dios le hubiera consultado cuando hizo el mundo, él le habria dado buenos consejosı" 13 . Aunque no dice de cuál rey de Castilla se trata, es de agradecer que Dios no le haya pedido consejo, pues no creo que la mitad de la población que forma el género femenino hubiera salido demasiado bien parada ${ }^{14}$.

Abandonando ahora a la marquesa para volver a Sofía también aqui nos encontramos con que el discurso se enreda en una trama de intriga donde la ignorancia de la protagonista juega un papel fundamental. Si en Fontenelle el hilo conductor es la pluralidad de mundos, en Gaarder es nada menos que la propia identidad, nuevamente cuestionada en nuestro siglo desde la época de Parménides. Podría decirse que en este caso, la elección de este tema viene dada por el orden cronológico que impone la Historia de la Filosofía, pero no es sólo eso; toda la estructura del libro es precisamente un juego entre la realidad y la imagen que pone justamente en cuestión la identidad del personaje.

"Ese día sólo habia una pequeña carta en el buzón y era para Sofía. "Sofía Amundsen" ponian en el pequeño sobre. "Camino del Trebol, 3». Eso eka todo, no ponía quién la enviaba, ni siquiera tenía sello. En cuanto hubo cerrado la puerta de la verja, Sofia abrió el sobre. Lo único que encontró fue una notita tan pequeña como el sobre que la contenia. En la notita ponía ¿Quién eres? No ponía nada más. No traía ni saludos, ni remitente, sólo esas dos palabras escritas a mano con grandes interrogaciones. Volvió a mirar el sobre. Pues sí, la carta era para ella. ¿Pero quién la había dejado en el buzón?„15.

En estas palabras aparece ya un triple elemento de misterio: en el fenómeno mismo, el descubrimiento de un sobre 
en el buzón que ni siquiera está segura de que fuera para ella; el causante o agente del mismo, ya que especificamente se dice que la carta carecia de remitente, y el tema de la carta, que pone en cuestión la identidad misma de su destinataria. "..Se dejó caer en una banqueta de la cocina con la misteriosa carta en la mano. ¿Quién eres? En realidad no lo sabia. Era Sofía Amundsen naturalmente, pero, ¿quién era eso? Aún no lo había averiguado del todo. Se puso de pie de un salto y entró en el cuarto de baño con la extraña carta en la mano. Se colocó delante del espejo y se miró fijamente a si misma. -Soy Sofía Amundsen- dijo. La chica del espejo no contestó ni con el más leve gesto. Hiciera lo que hiciera Sofía, la otra hacía exactamente lo mismo.... ¿Quién eres?- preguntó. No obtuvo respuesta tampoco ahora, pero durante un breve instante llegó a dudar si era ella o la del espejo la que habia hecho la preguntan ${ }^{16}$.

Parece claro, que el elemento de misterio al menos para la persona a la que va dirigida la formación e información que pretende el autor está vinculado a su propia ignorancia. Sofía nunca habia puesto en duda su propia identidad, ni la marquesa de Fontenelle había dudado jamás de la estabilidad y situación privilegiada de la Tierra. Ambos hechos, tan sumamente diferentes, parecen, sin embargo, desencadenar en el receptor actitudes que irán desde el miedo a la sorpresa o el agradecimiento de quien entiende que le han descubierto un nuevo mundo. Volviendo a Fontenelle la marquesa aprende la nueva tesis copernicana que supone a la Tierra girando alrededor del Sol y adopta, entonces, frente a Copérnico actitudes distintas cuando aquel le va descubriendo las consecuencias del nuevo sistema heliocéntrico.

"Os entiendo, -respondió- y amo la Luna por haberse quedado con nosotros cuando todos los planetas nos abandonaban. Confesad que si vuestro alemán [Copérnico] hubiera podido hacernosla perder, lo habria hecho gustoso, pues, en todo su proceder, veo que era muy mal intencionado para con la Tierra.

Yo le agradezco mucho -repliqué- el haber abatido la vanidad de los hombres que se habian puesto en el lugar más bello del universo, y me agrada ver a la Tierra entre la multitud de los planetas.

Bueno, -respondió- ¿creéis que la vanidad de los hombres se extiende hasta la astronomia? ¿Creeis haberme humillado por haberme enseñado que la Tierra gira alrededor del Sol? Os juro que no me estimo en menos por ello.
Dios mío, señora - proseguí- sé muy bien que será menos celoso de la jerarquía que se tenga en el universo que de la que se cree deber ocupar en un salón, y que la prelación de dos planetas no será jamás un asunto tan importante como el de dos embajadores. No obstante, la misma inclinación que hace que se quiera ocupar el lugar más honorable en una ceremonia, hace que un filósofo, si puede, se situe en un sistema en el centro del mundo. Le resulta agradable que todo esté hecho para él; da por supuesto, quizá sin darse cuenta, este principio que lo adula y su corazón no deja de interesarse por un asunto de pura especulación.

Francamente -replicó ella- esto es una calumnia que vos habeis inventado contra el género humano. Pues no habría debido aceptarse jamás el sistema de Copérnico si es tan humillante» 17 .

Las nuevas ideas expuestas por Fontenelle despiertan en la marquesa distintos sentimientos que van del estupor a la duda o al recelo, y algo parecido le ocurre la protagonista del libro de Gaarder, dejando en los dos casos traslucir el estilo paternalista al que aludi al principio.

En el caso de Sofía, como ya comenté, la protagonista es una adolescente, y además el personaje maestro aparece interferido con la figura del padre, con lo cual, el paternalismo queda, aparentemente, más justificado.

Ahora bien, si comparamos dos textos cuyo tema es el mismo, a saber: la explicación de la inversión copérnicana mostrando que es la Tierra la que se mueve y no el Sol como se habia pensado, las semejanzas entre ambas obras, en cuanto a las paculiaridades comentadas, resulta sorprendente: "Durante toda la Edad Media los hombres habían caminado bajo el cielo mirando hacia arriba al sol y a la luna, a las estrellas y a los planetas. Pero nadie había dudado de que la Tierra fuera el centro del universo. Ninguna observación habia dado lugar a que se dudase de que la Tierra estaba quieta y que fuesen los cuerpos celestes los que daban vueltas alrededor de ella. A esto lo llamamos visión geocéntrica del mundo, es decir, que todo gira alrededor de la Tierra. También la idea cristiana de que Dios dominaba sobre todos los cuerpos celestes contribuyó a mantener esta visión del mundo.

- Me gustaria que fuera así de sencillo.

Pero en 1543 salió un librito que se llamaba Sobre las revoluciones de los orbes celestes, escrito por el astrónomo pola-

ARBOR CLXXXI 716 NOVIEMBRE-DICIEMBRE (2005) 487-499 ISSN: 0210-1963 
co Copérnico. Copérnico sostuvo que no era el Sol el que giraba en órbita alrededor de la Tierra, sino al revés. Opinaba que esto era posible basándonos en las observaciones de que se disponía sobre los astros. El que los hombres hubieran pensado que el sol se movía en una órbita alrededor de la Tierra se debia simplemente a que la Tierra gira alrededor de su propio eje, decía. Señaló que todas las observaciones de los astros eran mucho más fáciles de comprender si se suponia que tanto la Tierra como los demás planetas se movian en órbitas circulares alrededor del sol.

- ¿Y ésa era una visión correcta del mundo?

* No del todo. Su punto principal, es decir, que la Tierra se mueve en una órbita alrededor del Sol, es evidentemente correcto....Copérnico creia, además, que la Tierra y los demás planetas hacian movimientos circulares alrededor del Sol» 18 .

El otro autor explica: «También el mismo Copérnico -prosegui- desconfió mucho del éxito de su opinión. Estuvo mucho tiempo sin quererla publicar. Finalmente se decidió a ello ante los ruegos de gentes muy dignas de consideración. Aún asi, el dia que le llevaron el primer ejemplar impreso de su libro, ¿sabeis qué hizo? Se murió. No quiso soportar todas las réplicas que preveía y se zafó hábilmente del asunto» ${ }^{19}$

Es dificil reconocer cuál de los dos va dirigido a una adolescente y cual a una persona adulta; es más, se diría que este último texto de Fontenelle tiene por destinataria a una adolescente y el otro, en todo caso, a una mujer adulta. $Y$ es que, efectivamente, la mujer del XVIII es considerada, salvo muy contadas excepciones, una menor de edad a la que hay que explicarle las cosas, desde su más completa ignorancia, y desde la plataforma, aún más grave de su mentalidad infantil.

En nuestro avanzado siglo XX las cosas han cambiado algo, evidentemente, pero tenemos aún filosofía para damas, si bien a estas damas ha habido que rebajarles la edad; es dificil pensar que nadie se dirija hoy a una mujer adulta, pre- tendiendo escribir un diálogo científico o filosófico, más o menos divulgativo, en los términos actualizados de Fontenelle. Es necesario para ello situar a la interlocutora en la edad adolescente de los 15 años, la misma edad que tenía, en su momento, la destinataria real de las cartas de Euler. Pero el libro de Gaarder sigue teniendo la estructura desigual, jerárquica, en la que el maestro es varón y el discípulo, necesitado de aprender, naturalmente, mujer. Por eso esta obra presenta una estructura platónica, destacando una serie de dualidades que están muy relacionadas. En El mundo de Sofía la dualidad de género se corresponde con la dualidad adulto/niño de tal manera que ya de antemano queda claramente asumido que el adulto es el varon y el niño, la mujer. A partir de ahi, el trato paternalista o el comportamiento infantil de la protagonista quedan justificados. Dicho de otra manera, esta estructura dual desarrolla dos importantes caracteristicas: la casi necesaria actitud paternalista del varón hacia su interlocutora, que hemos encontrado frecuentemente en la literatura anterior del XVIII pero que, pareciendo ya excluida del siglo $X X$, aparece camuflada en la relación genérica bajo la otra dualidad de adultoniño. Y, por otra parte, la edad de la protagonista justifica permanentemente reacciones infantiles, (que se pueden dar en el asombro desmesurado ante ciertas respuestas, en el miedo, o en la excesiva admiración hacia su maestro) que nos llevan a una asociación inconsciente de tales reacciones no sólo con su edad, sino también con su sexo.

Así pues, la filosofía para damas sigue hoy día estando vigente. No ha escogido Gaarder un varón como interlocutor válido de sus reflexiones, sino una mujer, depositaria de las caracteristicas que he explicado anteriormente. Únicamente, y de modo caritativo, cabe pensar que, en nuestro siglo, la elección de una quinceañera como destinataria de los profundos vericuetos por donde ha discurrido la filosofía se deba, por fín, al reconocimiento de una mayor y más temprana madurez de la mujer respecto del hombre, y que a esta edad ellas, y no ellos, estén capacitadas para acceder al oscuro, inquietante, tortuoso e intrigante mundo de la Filosofía que llega a cuestionar hasta la propia identidad. ¡Esperemos que asi sea! 


\section{NOTAS}

1 Gaardner,Jostein: El mundo de Sofía. Novela sobre la Historia de la Filosofía. Ed. Siruela, Madrid, 1994.

2 Euler, Leonhard: Reflexiones sobre el espacio, la fuerza y la materia, Introducción, traducción y notas, A.Rioja, Alianza , Madrid, 1985, p. 15-16.

3 Leibniz,G.W.: Filosofía para Princesas, Introducción, traducción y notas, J. Echeverría, Alianza, Madrid,1989, p. 25.

4 Euler, Op. cit. p. 16.

5 Fontenelle: Op. cit., p. 69.

6 Gaarder,J.: Op. cit., p. 1.

7 Idem, p. 9.

8 Fontenelle, Op. cit., p. 73.

9 Gaarder, Op. cit. p. 21

10 Idem, p. 23.

11 The author compares one of the philosophical best sellers, Sophia's World, with traditional "literature for Ladies", a very famous genre in the Enlightenment. The book supports masculine-feminine duality as well as adult-child and reality-appearance dualities.Fontenelle, Op. cit., p. 75.

12 Idem, p. 77.

13 Supongo que se trata de Alfonso $X$ el Sabio, autor de las Tablas Alfonsinas, que le permitieron confeccionar calendarios a partir de ciertas mediciones y observaciones del movimiento de los planetas.

14 Gaarder, Op. cit., p. 2.

15 Idem, p. 3.

16 Fontenelle: op. cit, p. 79.

17 Gaarder: Op. cilt., p. 248-249.

18 Fontenelle: Op. cit., p. 79. 